University of Nebraska - Lincoln

DigitalCommons@University of Nebraska - Lincoln

Faculty Publications from Nebraska Center for Research on Children, Youth, Families, and Schools
Children, Youth, Families \& Schools, Nebraska Center for Research on

2020

\title{
The Distal Role of Adolescents' Awareness of and Perceived Discrimination on Young Adults' Socioeconomic Attainment among Mexican-Origin Immigrant Families
}

Lorey Wheeler

Prerna G. Arora

Melissa Y. Delgado

Follow this and additional works at: https://digitalcommons.unl.edu/cyfsfacpub

Part of the Bilingual, Multilingual, and Multicultural Education Commons, Child Psychology Commons, Counseling Psychology Commons, Developmental Psychology Commons, Early Childhood Education Commons, Educational Psychology Commons, Family, Life Course, and Society Commons, and the Other Social and Behavioral Sciences Commons

This Article is brought to you for free and open access by the Children, Youth, Families \& Schools, Nebraska Center for Research on at DigitalCommons@University of Nebraska - Lincoln. It has been accepted for inclusion in Faculty Publications from Nebraska Center for Research on Children, Youth, Families, and Schools by an authorized administrator of DigitalCommons@University of Nebraska - Lincoln. 


\title{
The Distal Role of Adolescents' Awareness of and Perceived Discrimination on Young Adults' Socioeconomic Attainment among Mexican-Origin Immigrant Families
}

\author{
Lorey A. Wheeler, ${ }^{1}$ Prerna G. Arora, ${ }^{2}$ \& Melissa Y. Delgado ${ }^{3}$
}

\author{
1 Nebraska Center for Research on Children, Youth, Families and Schools, \\ University of Nebraska-Lincoln, PO Box 830858, Lincoln, NE 68583-0858 \\ 2 Department of Health and Behavior Studies, Teachers College, Columbia \\ University, 525 West 120th Street, New York, NY 10027 \\ 3 Norton School of Family and Consumer Sciences, University of Arizona, \\ McClelland Park, 650N Park Ave, Tucson, AZ 85721- 0078 \\ Corresponding author — Lorey A. Wheeler, lorey@unl.edu
}

\begin{abstract}
Cultural-ecological frameworks posit that there are harmful effects of social stratification on developmental outcomes. In particular, awareness of aspects of social stratification in society and interpersonal experiences of discrimination, more generally and within specific contexts, may differentially influence outcomes across life stages; yet, few studies have examined the distal effects during adolescence on early adult developmental outcomes. The current study fills this gap by examining distal mechanisms linking adolescents' (Time 1: ages 13-15) awareness of and perceived general and school discrimination to young adults' (Time 3: ages 23-25) socioeconomic attainment (i.e., educational attainment, occupational prestige, earned income) through adolescents' (Time 2: ages 16-18) academic adjustment (i.e., grades and educational expectations). The study also examined variation by adaptive culture (i.e., English and
\end{abstract}

Published in Journal of Youth and Adolescence 49 (2020), pp 2441-2458.

doi:10.1007/s10964-020-01276-0

Copyright (C) Springer Science+Business Media, LLC, part of Springer Nature 2020. Used by permission.

Submitted 28 January 2020; accepted 12 June 2020; published 25 June 2020. 
Spanish language use behavior, familism values) and youth gender. Data are from the Children of Immigrants Longitudinal Study $(N=755$ Mexican-origin adolescents and their foreign-born parents; $51.5 \%$ male adolescents; Time $1 M$ age $=14.20$ years). The results revealed that adolescent's awareness of societal discrimination (Time 1) related to adolescents' higher grades (Time 2), which, in turn, related to higher educational attainment and occupational prestige in early adulthood (Time 3 ). For young women, but not men, sources of perceived discrimination within the school context during adolescence related to lower educational attainment. Additional variation by adaptive culture and gender was also found. Implications discussed are related to positive development among Mexican-origin youth in immigrant families.

Keywords: Adolescence, Culture, Discrimination, Mexican-origin immigrant families, Socioeconomic attainment, Early adulthood

\section{Introduction}

Mexican Americans, who constitute 63\% (U.S. Census Bureau 2017) of Latinos ${ }^{1}$ residing within the U.S. (18.3\% of U.S. population; U.S. Census Bureau 2019), are the largest ethnic group among U.S. immigrants (López et al. 2018). Youth in these families are one of the fastest growing segments within U.S. schools (López et al. 2018). Even though most Latino students do well in school, educational disparities between these youth and White youth remain (e.g., graduation rates and college-going; McFarland et al. 2017). These disparities have large societal and individual costs that relate to academic attainment, poverty, low occupational prestige and unstable employment (Snyder et al. 2019), and higher rates of psychosocial, behavioral, and physical health problems (Sum et al. 2009). To understand potential opportunity gaps to minimize disparities, it is critical to understand proximal and distal mechanisms that explain variation in socioeconomic attainment among Mexican-origin youth in immigrant families. For youth in immigrant families, experiences of racism and oppression (social stratification mechanisms) may play a critical role in gaps and disparities (Stein et al. 2016). Thus, the current study examined the distal links between social stratification mechanisms during adolescence on young adults' socioeconomic attainment, as well as the roles of youth's adaptive culture and gender among Mexican-origin immigrant families.

1. Here the term "Latinos" refers to people of Latin American origin, cultural or ethnic identity in the United States. 


\section{Mechanisms of Social Stratification}

The integrative model stresses the importance of investigating macrosystem level mechanisms when examining developmental outcomes among ethnic minority and immigrant youth (Stein et al. 2016). One mechanism hypothesized to contribute negatively to academic achievement and expectations and the resulting disparities in socioeconomic attainment is social stratification (e.g., racism, awareness, discrimination based on group membership; Stein et al. 2016). Racism refers to assumptions of inherent superiority of particular racial or cultural groups in a context resulting in prejudice (i.e., preconceived judgements made about a person based on group membership) and discrimination (i.e., behaviors denying equal treatment of members of ethnic, racial, or immigrant groups) against other groups (Stein et al. 2016). Mexican-origin youth frequently report experiencing discriminatory treatment in multiple contexts, including schools and other public spaces (Delgado et al. 2019). Experiences of discrimination have been found to increase during adolescence (Zeiders et al. 2018) and have been noted to be more harmful to long-term development than in early adulthood (Adam et al. 2015). This research suggests that adolescence, a developmental period rife with physical, social, and cognitive changes, may be a particularly sensitive period. Moreover, some literature has suggested that beyond direct experiences/ perceptions of discrimination, youths' awareness of racism/discrimination within a society may also be of import (Diemer et al. 2016). This emerging literature suggests that youth's awareness and understanding of social stratification as it contributes to inequalities in society can play an important role in developmental outcomes for those marginalized by these forces (Diemer et al. 2016). Similar to perceived discrimination, there is some evidence that youth's awareness of discrimination increases across adolescence among Latino youth (Seider et al. 2019).

\section{Discrimination, Academic Adjustment, and Socioeconomic Attainment}

The expectancy-value model of achievement suggests that academic expectations and behaviors during adolescence influence educational choices affecting later attainment; it also suggests that expectations for 
success and attainment are strongly rooted in the social, economic, and cultural aspects of environments with which youth interact (Wigfield and Cambria 2010). For ethnic minority youth, social stratification experiences may be particularly salient. Perceived discrimination experienced within a particular context or environment, such as schools, or a more general awareness of that discrimination occurring could lead to youth perceiving these contexts as inhibiting rather than promotive (Stein et al. 2016). Thus, these aspects of social stratification may contribute to less engagement and poorer academic adjustment, ultimately relating to socioeconomic disparities in early adulthood. Empirical findings for Latino populations document cross-sectional and longitudinal links between perceived discrimination during adolescence with indicators of academic adjustment, such as adolescents' academic performance (grade point average; general discrimination; Huynh and Fuligni 2010; school discrimination; Benner and Graham 2013). Within adult samples, indicators of discrimination have been linked to socioeconomic attainment (i.e., educational attainment, occupational prestige, and earned income; see Araújo and Borrell 2006 for review). The few studies that have examined awareness of discrimination have found associations with indicators of academic adjustment (negative link to school belonging, but not academic performance; Brown and Chu 2012). Other studies have linked awareness to poorer mental health outcomes among Latino adolescents in immigrant families (Ríos-Salas and Larson 2015). There is a paucity of work that has examined links with socioeconomic attainment.

In reviewing this literature, there are also studies that suggest no direct link between perceived discrimination and academic performance in studies with Latino students (62\% Mexican origin, general discrimination; Benner and Graham 2011), or with Mexican immigrant children in predominantly White communities (school discrimination; Brown and Chu 2012). There are similar null findings for awareness of societal discrimination (Benner and Graham 2013; Stone and Han 2005). Other studies find only subgroup effects, particularly for Latino (general discrimination; Alfaro et al. 2009) and Mexican-origin (general discrimination; Umaña-Taylor et al. 2012) boys. In understanding the variation in findings, relatively little scholarship has specifically focused on understanding the potential differential impact across sources. Some studies have measured perceptions of discrimination more generally (Huynh and Fuligni 2010; Umaña-Taylor et al. 2012) or across contexts (Alfaro 
et al. 2009; Benner and Graham 2011), in relation to the school context (peers and teachers, Berkel et al. 2010; Brown and Chu 2012; teachers, Stone and Han 2005; school personnel, Benner and Graham 2013), or awareness of societal/community-level discrimination (awareness of societal discrimination, Stone and Han 2005; community attitudes toward immigrants, Brown and Chu 2012). These varied findings may suggest a need for further understanding of differential mechanisms that link sources of social stratification to outcomes. Alternatively, these findings may suggest the importance of understanding within-group variation in these linkages (e.g., gender) across multiple indicators of social stratification, including awareness of and experiencing/perceiving discrimination more generally or in particular contexts. The current study examined both alternative explanations by considering the salience of different experiences with social stratification, either through awareness of or perceiving interpersonal discrimination more generally or within the school context, among Mexican-origin youth in immigrant families. These effects of discrimination were examined in relation to central developmental competencies in the area of academic adjustment and socioeconomic attainment as informed by the integrative (Stein et al. 2016) and expectancy-value (Wigfield and Cambria 2010) models.

\section{The Role of Adaptive Culture}

The role of adaptive culture is important when considering contextual protective resources related to academic outcomes (Perez-Brena et al. 2018). Adaptive culture refers to a set of goals, values, and beliefs that may vary from the dominant culture (Perez-Brena et al. 2018). The degree to which individuals are oriented to the values, beliefs, and members of a particular cultural group (i.e., cultural orientation; Perez-Brena et al. 2018) is believed to be especially salient in understanding educational success and attainment in the U.S. among immigrant families (Gonzales et al. 2004). For youth in immigrant families, an important aspect of adaptive culture is how they orient toward traditional Mexican (e.g., Spanish language ability, traditional Mexican cultural value of familism) and mainstream U.S. (e.g., English language ability) culture (Stein et al. 2016). There is research that shows the promise of either the promotive (e.g., direct or mediating effects; risk reduction) or the protective (e.g., moderating-buffering role) role of cultural orientation on outcomes. 
This literature has focused primarily on psychosocial or academic adjustment, with a paucity of empirical work examining the role of cultural orientations on the association between mechanisms of social stratification and socioeconomic outcomes. The current study aimed to address this gap.

\section{Promotive mechanisms}

Experiences with aspects of social stratification, such as awareness of discrimination with society and perceived interpersonal experiences of discrimination, may shape youth's responses that ultimately influence developmental outcomes. It has been suggested that experiences in relation to discrimination may shape processes of social and ethnic identity (Greene et al. 2006), thus potentially influencing youth endorsements of mainstream and Mexican culture. Indeed, adolescents' perceived discrimination by teachers has been linked to both higher probabilities of English and foreign-language use among diverse adolescents in immigrant families; awareness of societal discrimination positively linked only to English language use (Medvedeva 2010). Yet, perceived discrimination from peers has been negatively linked to English language use (Medvedeva 2010). Suggesting source of discrimination may matter. Moreover, some scholars have suggested that cultural orientations could provide a source of resilience in contexts of discrimination (Berkel et al. 2010).

In the broader academic literature, there is some empirical support for the promotive nature of endorsing an orientation toward Mexican culture (i.e., Spanish language ability and Mexican cultural values). In turn, use of Spanish language among mothers (Dumka et al. 2009) and in the home, more generally (Blair and Cobas 2006), has been associated with better academic outcomes among Latino and Mexican-origin females. Mexican cultural values (e.g., familism values) have also been related to increased academic engagement (Gonzales et al. 2008) and GPA (Berkel et al. 2010). In one of the few studies examining Mexican cultural orientation as a mediator between the association of discrimination and academic outcomes, Berkel et al. (2010) found that Mexican values (i.e., familism values, respect, religiosity) mediated the link between adolescents' school discrimination and GPA (i.e., discrimination related to higher Mexican cultural values, which, in turn, related 
to higher GPA); moderation by Mexican values was also tested but not supported. Conversely, there is also support of the promotive nature of endorsing a mainstream cultural orientation. For example, English language ability (mainstream orientation) has also been found to promote better academic outcomes (grades; Santiago et al. 2014), educational attainment (Roche et al. 2012), and better socioeconomic prospects (Chiswick and Miller 2007). There is a paucity of work that has examined English or Spanish language ability as mediators; though, as previously discussed, links are supported between discrimination and language ability, and language ability and youth outcomes, providing the basis for the current study.

Protective mechanisms

There is also some work that suggests that the magnitude of the link between discrimination and youth adjustment may vary based on cultural adaptation processes, such as high or low endorsements of cultural orientations (Stein et al. 2016). For traditional Mexican orientation, scholars have argued that a strong orientation toward one's cultural group either through endorsement of cultural values, such as familism, or behavioral indicators, such as retention of Spanish language use, may buffer the negative effects of risk (Perez-Brena et al. 2018). The empirical work on Mexican orientation as a protective factor has found some evidence in relation to psychosocial outcomes (e.g., familism values; Germán et al. 2009; Latino cultural orientation; Cavanaugh et al. 2018). There has been limited work on the moderating role of Mexican cultural orientation within the context of discrimination and socioeconomic outcomes. Conversely, for mainstream orientation, the findings are mixed. With psychosocial outcomes, a mainstream orientation has buffered the link between perceived general discrimination and risk behavior among Mexican-origin adolescents (Delgado et al. 2011), whereas for depressive symptoms, it has exacerbated the risk of perceived general discrimination among Mexicanorigin adults (English language use; Finch et al. 2000). For academic outcomes, there is evidence that for Chinese American youth who endorsed a high mainstream orientation, there was a stronger negative link between perceived general discrimination and grades (Benner and Kim 2009). Given these mixed prior findings and the need for 
elucidating the role of cultural orientations for Mexican-origin immigrant families (Perez-Brena et al. 2018), the current study extended the literature to examine both moderating and mediating mechanisms. The current study also examined mainstream and Mexican cultural orientations simultaneously, given there is some research suggesting the importance of successfully navigating both mainstream and Mexican cultural contexts (Perez-Brena et al. 2018).

\section{The Role of Individual and Structural Characteristics}

The integrative model considers other important individual and structural characteristics as informing developmental outcomes (Stein et al. 2016). In particular, youth gender is noted as an important individual characteristic. With regard to Mexican-origin immigrant families, a salient aspect is the role of gender as an organizing feature (Rafaelli and Ontai 2004). There is some evidence of variation in findings by gender. For example, empirical work points to differences in levels of academic adjustment (e.g., grades, competence, motivation) for the Mexican-origin population, with girls typically showing higher levels than boys (PiñaWatson et al. 2016). Conversely, boys have been found to report higher levels of perceived discrimination (from adults and peers) than girls (Huynh and Fuligni 2010). Moreover, meta-analytic work found stronger links of perceived discrimination for Latino boys' academics compared to Latino girls' and African-descent boys' (Benner et al. 2018). Given that discrimination is generally experienced outside of the family context, boys' greater freedom and encouragement to spend time in extra-familial contexts (Raffaelli and Ontai 2004) may partially explain why boys', as compared to girls', adjustment is more strongly influenced (Alfaro et al. 2009). Thus, attention to gender may point to individual differences to better inform interventions targeting gender and ethnic educational disparities (McFarland et al. 2017). The potential confounding effects of other important individual (time in the U.S., Roche et al. 2017; youth age and school enrollment status, Portes and Rumbaut 2001) and structural characteristics (socioeconomic status, Roche et al. 2017; family structure, Roosa et al. 2012) as suggested by prior literature on youth achievement were also taken into account as covariates. 


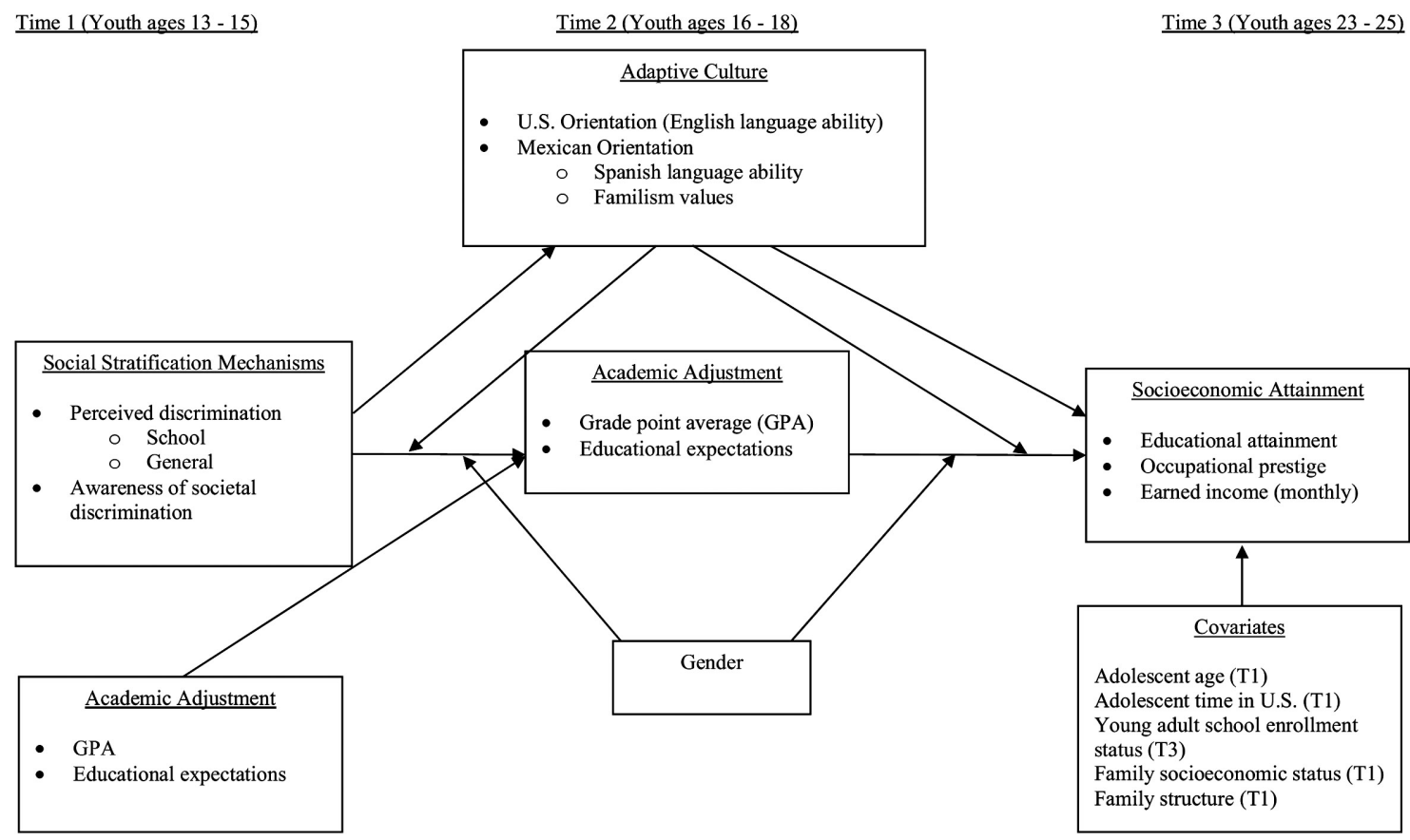

Figure 1 Conceptual model of longitudinal links between youth's experiences with discrimination (awareness of or interpersonal experiences) and socioeconomic attainment, through adolescents' academic adjustment among Mexican-origin immigrant families (Aim 1), alternative models of variation by adaptive culture (Aim 2: comparison of models as mediators or moderators), and adolescents' gender (Aim 3: moderator)

\section{Current Study}

The current study fills gaps in the literature by using an ethnic-homogenous design to examine the distal and lasting effects of discrimination on early adult socioeconomic among Mexican-origin immigrant families. The first aim was to examine the prospective links between adolescents' awareness of societal discrimination, and perceived general and school discrimination with indicators of young adults' socioeconomic attainment (i.e., educational attainment, occupational prestige, earned income) via adolescents' academic adjustment (i.e., academic performance [grade point average] and expectations) (see Figure $\mathbf{1}$ for conceptual model). It was hypothesized that higher awareness of and more perceived interpersonal discrimination would relate to poorer academic and socioeconomic outcomes. The second aim was to examine the role of adaptive culture (i.e., mainstream and Mexican cultural orientation) 
on the links between social stratification and academic adjustment and socioeconomic attainment. Alternative models were tested including indicators of cultural orientation as either mediators or moderators. The current study extends the literature by examining both mainstream (i.e., English language ability) and Mexican (i.e., Spanish langue ability, familism values) cultural orientations. Due to the mixed nature of the prior literature, the current study did not have specific hypotheses about the role of cultural orientations. The third aim was to examine variation in the linkages by gender and hypothesized the impact of perceived discrimination will be greater for boys than for girls (Benner et al. 2018).

\section{Methods}

Data came from the Children of Immigrants Longitudinal Study (CILS; Portes and Rumbaut 1991-2006), a study focused on youth ( $N=5262$; $51 \%$ female) with immigrant parents. Eligibility criteria for the study included the following: (a) youth with at least one foreign-born parent, (b) U.S.-born or born abroad but immigrated to the U.S. at an early age, and (c) in the 8th or 9th grade (study defined as second-generation immigrants). Participants included ethnically diverse students from 49 schools in the Miami/Ft. Lauderdale and San Diego metropolitan areas who were assessed in their preference language in 1992, 3 years later (1995; 82\% response rate), and 6-8 years later (2001-2003; 69\% response rate from Time 1; 84\% response rate from Time 2). This 11-year time-frame represents a period of increased immigrant growth in the U.S., with a large percentage coming from Mexico and other Latin American countries (Urban Institute 2009). The original study had Internal Review Board approval.

\section{Participants}

The current study used three waves (here referred to as Time 1 or T1, Time 2 or T2, and Time 3 or T3) of data from the Mexican-origin subsample $(n=755,14 \%$ of original sample; $51.5 \%$ male; $96 \%$ from San Diego) because of the interest in educational attainment particularly within this large U.S. immigrant subpopulation. Sixty percent of adolescents were born in the U.S. and had a foreign-born parent (90\% fathers; 92\% mothers). At T1, most adolescents considered their family's current 
economic situation to be lower-middle class (43\%), 58.27\% (SD=22.29) were eligible for subsidized school lunch and lived with both parents (64.3\%). Mothers and fathers were on average $38.19(S D=5.97)$ and $41.32(S D=7.95)$ years of age, respectively. Adolescents averaged 14.20 years $(S D=0.87)$ and $97 \%$ spoke Spanish. Adolescents attended 35 different schools, the majority (96\%) included less than 59\% total student enrollment that were either Black or Hispanic. At T3, 66\% of youth were employed, $17.5 \%$ were employed part-time, and $16.5 \%$ were not working; $59.3 \%$ of youth were not attending school.

Of the 755 Mexican-origin youth surveyed at T1, 79\% ( $n=599 ; M$ age $=17.81, S D=0.78$ ) participated in the survey at $\mathrm{T} 2$, and $56 \%$ participated in the survey at T3 $(n=424 ; M$ age $=24.15, S D=0.86)$. Demographic differences existed between youth who remained in the study versus those who did not. Compared to those who remained in the study over time, youth lost to attrition at T2 were significantly older $(M=14.17$, $S D=0.85 ; M=14.32, S D=0.94$, respectively), reported more sources of general discrimination $(M=1.09, S D=1.05 ; M=1.38, S D=1.07$, respectively), lower educational expectations $(M=3.75, S D=1.08 ; M=3.53, S D$ $=1.18$, respectively), and lower GPA $(M=2.31, S D=0.83 ; M=1.99, S D=$ 0.87 , respectively). Youth lost to attrition at T3 were more likely to be male, residing in U.S. for less than 5 years, Spanish language dominant, lower GPA ( $M=2.10, S D=0.86 ; M=2.36, S D=0.83$, respectively), and had lower family socioeconomic status $(M=-0.72, S D=0.65 ; M=-0.58, S D$ $=0.60$, respectively) than those remaining in the study. Attrition rates are consistent with other longitudinal studies of adolescents (Martinez and Bámaca-Colbert 2019) or young adults (Galambos and Krahn 2008). These variables were included in the analyses to account for attrition (in relation to missing data) to produce more robust and less biased model parameters (Enders 2010).

\section{Measures}

\section{Perceived discrimination (T1)}

To measure adolescents' perceived discrimination, two scales from CILS were used, as prior research suggests differential effects of sources of discrimination on educational adjustment (Benner and Graham 2013). Though not referenced in the item wording, an analysis of survey items 
asking about the reasons for discrimination, participants' overwhelmingly reported reasons related to racial or ethnic background (Stone and Han 2005).

General discrimination To measure perceived general discrimination, adolescents reported on four items representing if they have ever felt they have been discriminated against, and if they felt they have ever been discriminated against by White Americans, Latinos, or African Americans, in general were used. Responses for all items were $1=$ yes, $0=$ no (scores ranged from 0-4).

School discrimination To measure perceived school discrimination, adolescents' reports on three items asking if they felt they have ever been discriminated against by teachers, students, or counselors $(1=$ yes, $0=$ no) were used. Following procedures in prior discrimination literature (Rivas-Drake et al. 2009), items were summed within each source separately (scores ranged: $0-3$ ).

\section{Awareness of societal discrimination (T1)}

To measure adolescents' awareness of societal racism/discrimination against ethnic or immigrant groups, a mean was calculated from three items of Portes and Bach's (1985) Perceptions of Society and Discrimination Index (i.e., "There is racial discrimination in economic opportunities in the U.S.", "There is much conflict between different racial and ethnic groups in the U.S.", and "Americans generally feel superior to foreigners"; $\alpha=0.58$ ). Responses were on a Likert-type scale that ranged from $1=$ disagrees a lot to $4=$ agrees a lot.

\section{Academic adjustment (T1, T2)}

As indicators of academic adjustment, adolescents' reports of GPA and educational expectations were used.

Grade point average (GPA) GPA was on a scale of 0 to 5, with high scores representing high educational achievement. 
Educational expectations To assess educational expectations, adolescents reported on: "Realistically speaking, what is the highest level of education that you think you will get?" Responses were on a 5-point Likert scale representing the expected level of education ( $1=$ less than high school to 5 = finish a graduate degree).

\section{Socioeconomic attainment (T3)}

As indicators of young adult's socioeconomic attainment, educational attainment, occupational prestige, and personal earned income were used.

Educational attainment To assess educational attainment, young adults reported on the highest grade or year of school completed. Data were collected on a 9-point scale (1 = Some high school [grades 9-12, no diploma] to $9=$ Professional/Doctoral degree [JD, MD, DDS, Ph.D.]). The original study investigators recoded responses to represent the highest total number of years of education completed.

Occupational prestige To assess occupational prestige, young adults reported on: "Currently, what is your main occupation or job-that is, the paid job you spend the most time at now". The original study investigators recoded responses to Treiman prestige score ranging from 0 to 100, with high scores representing more prestige (Treiman 1977).

Earned income Young adults responded to the question: "Approximately, how much do you earn per month from all sources?". This item was standardized to assess earned income.

\section{Cultural orientations (T2)}

As indicators of adaptive culture, three measures of cultural orientations (i.e., English and Spanish language ability, familism values) were used.

Language ability The CILS included a 4-item measure of English language ability and Spanish language ability that were used as indicators of adolescents' behavioral cultural orientations (toward U.S. mainstream culture and Mexican culture, respectively). The items asked about adolescents' ability to speak, read, write, and understand English and 
Spanish. Responses were on a 4 -point Likert scale $(1=$ Not at all to $4=$ Very well) and averaged to create scales (English: $\alpha=0.94$; Spanish: $\alpha$ $=0.92$ ).

Familism values The CILS included the 3-item Components of Familism Scale (Portes and Rumbaut 2001). This scale represents cultural values related to the centrality of family (e.g., family attachment, loyalty, and solidarity, placing the family before one's own personal needs) as an additional measure capturing youth's orientation toward Mexican culture. Adolescents reported on items related to preference to choose a relative rather than a friend for help finding a job, perceiving relatives as the best source of help for a problem, and the importance of getting a job near parents. These items have been used in prior research on adolescent development and relate to other indicators of Mexican-origin youth's Mexican cultural orientation (Roche et al. 2012). Responses, on a 4-point Likert scale ( 1 = Disagree a lot to 4 =Agree a lot), were averaged $(\alpha=0.60)$.

\section{Individual and structural characteristics}

Covariates included adolescents' gender, age in years, length of time in U.S., family structure, and family socioeconomic status (SES) from T1; T3 enrollment in school was also used.

Gender Adolescents' reported their gender as either female (0) or male (1).

Length of time in U.S. Time in the U.S. was constructed from adolescents' report on one question, "How long have you lived in the U.S.?" Responses were on a 4 -point scale, $1=$ all my life, $2=10$ years or more, $3=5-9$ years, $4=<5$ years. Based on prior research by Roche and colleagues (2017) that found differences between adolescents in the U.S. for $<5$ years compared to other categories, the categories were collapsed $(0=\geq 5$ years, $1=<5$ years $)$.

Family structure Adolescents reported on one question related to household guardians (i.e., "Which of the following best describes your present situation?") that was recoded to represent family structure (0 = single-parent household, 1 = two-parent household). 
Family socioeconomic status (SES) Family SES was a unit-weighted standardized scale of father's and mother's education and occupational prestige scores, plus family home ownership. Scores were computed for cases with data on three or more of the variables. School enrollment status T3 reports of whether youth were enrolled in a school/college were included $(0=$ not enrolled, $1=$ enrolled $)$.

\section{Data Analytic Approach}

Path analysis within a structural equation modeling (SEM) framework in Mplus 7.3 (Muthén and Muthén 1998-2014) was used. Adequate model fit was evaluated using the chi-square statistic, the Root Mean Square Error of Approximation (RMSEA $\leq 0.08$ ), and Comparative Fit Index (CFI $\geq 0.95$ ) (Hu and Bentler 1999). Full information maximum likelihood (FIML) was used to maintain power by retaining all cases with data at Time $1(N=755)$ for use in all analyses and improve estimation under conditions of missing data (Enders 2010). Simulation studies suggest that FIML is robust under conditions of $50 \%$ or more missing data (Enders 2010). To meet assumptions of data Missing at Random (Enders 2010), auxiliary (T1 English and Spanish language ability) variables and covariates (T1 gender, age, time in the U.S., GPA, educational expectations, family SES and structure, and T3 in-school status) related to missingness and dependent variables were included in all models. This approach produces more robust and less biased model parameters under conditions of missing data (Enders 2010). The indirect (mediation) pathways (Aims 1 and 2) were examined using the product of coefficients method using bias-corrected bootstrapping with 1000 resamples to calculate the confidence intervals (CI; Fritz et al. 2012). In testing for moderation, two methods were used, either by including interaction terms for the continuous moderators (Aim 2) or the use of multiple-group models for gender (Aim 3).

\section{Results}

Descriptive statistics and correlations among all study variables are reported in Table 1. For ease, the findings for Aim 3 (moderation by gender) were integrated within the sections for Aims 1 and 2. Gender 


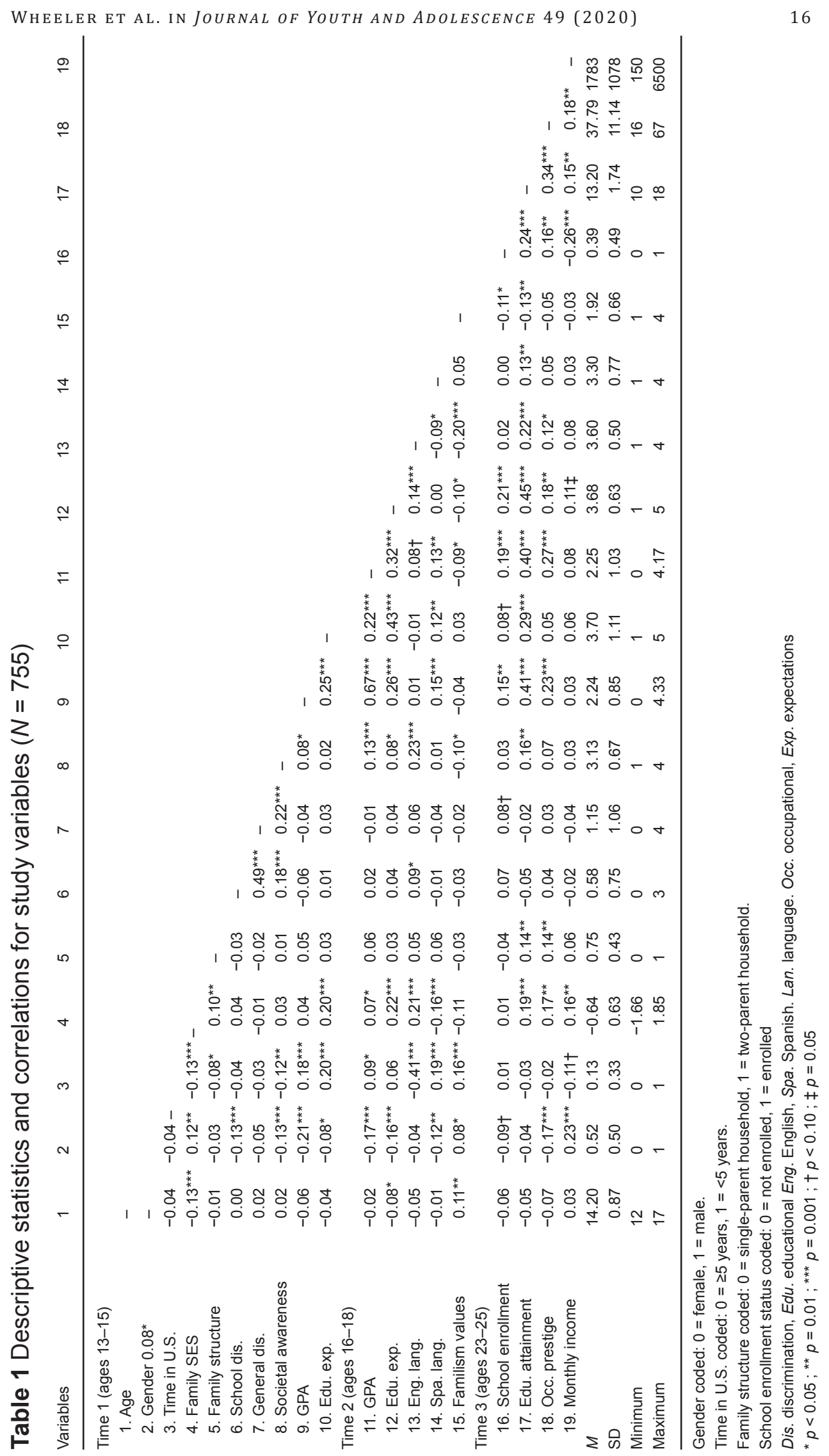


moderation was tested by estimating a series of multiple-group path models, identifying regression coefficients that were significant for one group and not the other or when coefficient signs differed across groups. Model fit was compared; one in which the coefficient of interest was constrained to be equal across groups to the model in which it was free to vary across groups. Evidence of moderation is described below when the constrained model resulted in a significant change in $\chi^{2}, p<0.05$ and fit indices indicated that the unconstrained model fit significantly better than the constrained model (Kline 2011).

\section{Awareness and Perceived Discrimination Related to Socioeconomic Attainment}

For Aim 1, a series of path models tested the hypothesized relationships between indicators of awareness of societal discrimination, perceived school and general discrimination (T1), academic adjustment (T2), and socioeconomic attainment (T3). Results indicated good model fit and explanation of a moderate to large amount of variance in the indicators of academic adjustment and socioeconomic attainment (Figure 2). Findings for the covariates (for simplicity, standardized path coefficients presented in text and not in Figure 2) suggested that GPA, $\beta=0.65, S E=0.03$, $p<0.001$, and educational expectations, $\beta=0.42, S E=0.04, p<0.001$, were stable over time. Gender related to occupational prestige, $\beta=-0.13$, $S E=1.26, p=0.019$, and earned income, $\beta=0.24, S E=0.12, p<0.001$, such that females had higher levels of prestige and males had higher levels of monthly earned income. Adolescents' time in the U.S. (T1) related to earned income (T3), such that those having been in the U.S. longer have higher income, $\beta=-0.10, S E=0.12, p=0.010$. Adolescents' familyof-origin SES (T1) was related to higher occupational prestige in early adulthood (T3), $\beta=0.14, S E=1.00, p=0.016$. Family structure (T1) related to educational attainment, $\beta=0.12, S E=0.18, p=0.012$, and occupational prestige, $\beta=0.12, S E=1.45, p=0.040$, such that adolescents living in a two-parent household (T1) had higher educational attainment and occupational prestige in early adulthood (T3).

Findings for the primary research question were partially in contrast to hypotheses and suggested that adolescents' reports of awareness of societal discrimination (T1) related to increased adolescent GPA (T2) and higher young adult educational attainment (T3) (Figure 2). As 
$\underline{\text { Time } 1 \text { (Youth ages } 13-15)}$

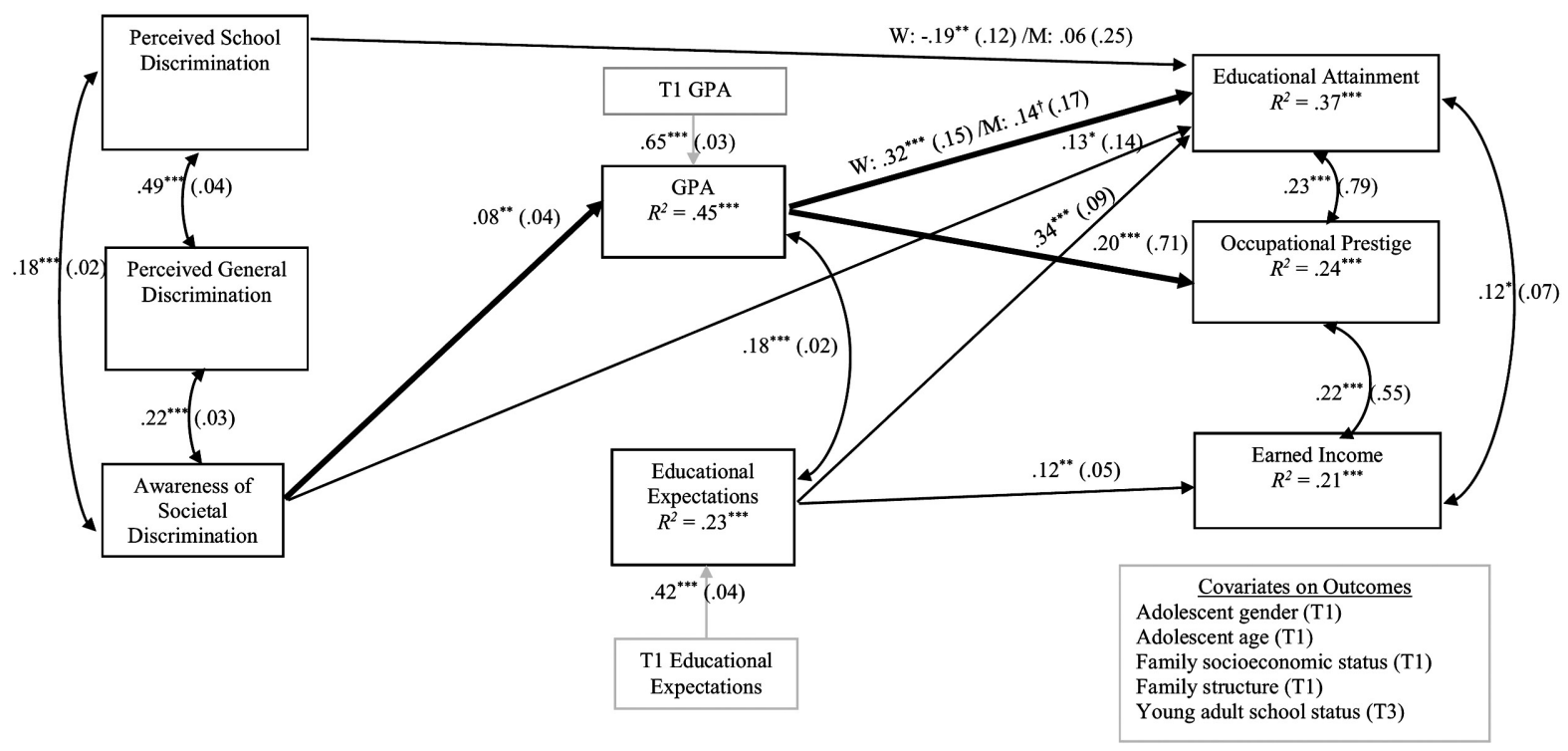

Figure 2 Significant $(p<0.05)$ standardized (standard error) findings Aim 1: longitudinal links between experiences with discrimination (awareness of or interpersonal experiences) and Mexican-origin youth's socioeconomic attainment, with variation by gender (Aim 3). $N=755$. Model fit: $\chi^{2}(20)=87.68, p<0.001$. RMSEA $=0.067,90 \% \mathrm{CI}$ $[0.053,0.082]$. CFI: 0.925 . SRMR $=0.041$. The covariate parameter estimates not included here to simplify figure (see text for estimates). Significant $(p<0.05)$ indirect effects noted by bold lines. Societal discrimination to adolescent GPA $[a b=0.054 ; 95 \% \mathrm{CI}$ $=0.022,0.105]$ to young adult educational attainment. Societal discrimination to adolescent grades $[a b=0.272 ; 95 \% \mathrm{CI}=0.088,0.596]$ to young adult occupational prestige. Gender moderation: estimate for women before the slash, for men after the slash. $R^{2}$ can be interpreted as effect sizes (small $=0.02$, medium $=0.13$, large $=0.26$; Cohen 1992). $\dagger p<0.10,{ }^{*} p<0.05,{ }^{* *} p=0.01,{ }^{* * *} p=0.001$

expected, adolescents increased educational expectations (T2) related to higher educational attainment and earned income in early adulthood (T3). As expected, adolescents' GPA (T2) was related to higher educational attainment and occupational prestige in early adulthood (T3). The link between GPA (T2) and educational attainment (T3), was moderated by gender (Aim 3), suggesting a stronger link for female adolescents, as compared to male adolescents, $\Delta \chi^{2}(1)=4.52, p=0.033$. The tests of gender moderation also revealed an additional relationship. Results suggested that for female adolescents, but not males, perceptions of school discrimination related to lower educational attainment, $\Delta \chi^{2}$ (1) $=4.52, p=0.033$. 
Turning to the tests for the indirect associations (mediation) between adolescents' perceived discrimination and young adults' socioeconomic attainment, findings revealed significant pathways (Figure 2). Findings suggested that adolescents' awareness of societal discrimination related to increased adolescent GPA, which, in turn, related to higher educational attainment and occupational prestige.

\section{The Role of Adaptive Culture}

For Aim 2, the adaptive culture variables (i.e., T2 English language ability as an indicator of U.S. cultural orientation, Spanish language ability and familism values as indicators of Mexican orientation) were added to the model used to test Aim 1. Two models were estimated, one testing for adaptive culture as T2 mediators between awareness and experiences of discrimination (T2) and young adult socioeconomic outcomes (T3). Covariance between the T2 indicators of adaptive culture (mediators) and T2 academic adjustment were included; paths were not included to maintain temporal precedence in the mediation pathways. The second model tested for moderation on the associations between awareness and experiences of discrimination with adolescents' academic adjustment and young adults' socioeconomic adjustment. For tests of moderation, interaction terms that contained the moderator of interest (i.e., T2 English and Spanish language ability, familism values) by the discrimination variables (e.g., English language ability

$\times$ perceived general discrimination) were included. All variables were centered prior to the creation of the interaction terms to reduce multicollinearity (Aiken and West 1991).

The chi-square difference test suggested that the moderation model fit the data better than the mediation model, $\Delta \chi^{2}(34)=153.34, p<0.001$. The final models presented include only significant interaction terms as retaining those not significant contributes to an increase in standard errors (Aiken and West 1991; Table 2). Follow-up simple slopes analyses were conducted as outlined by Aiken and West (1991), including plotting and testing for significant simple slopes $+1 S D$ above and $-1 S D$ below the mean. Results of the path analyses for the moderation model indicated good model fit and explanation of additional variance (moderate to large) above the model for Aim 1 (Table 2). Results discussed here pertain to the indicators of adaptive culture. Starting with adolescents' 


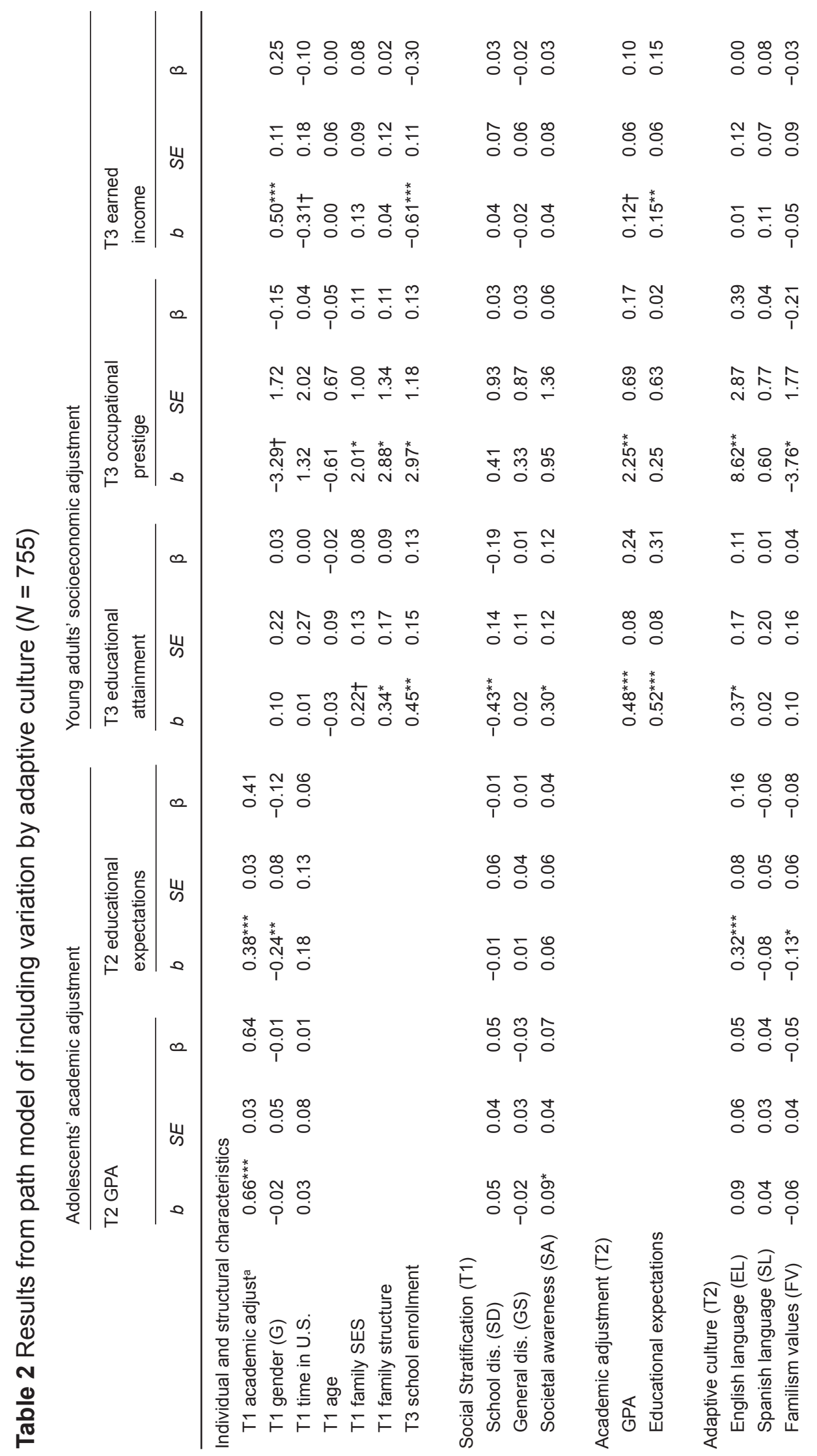




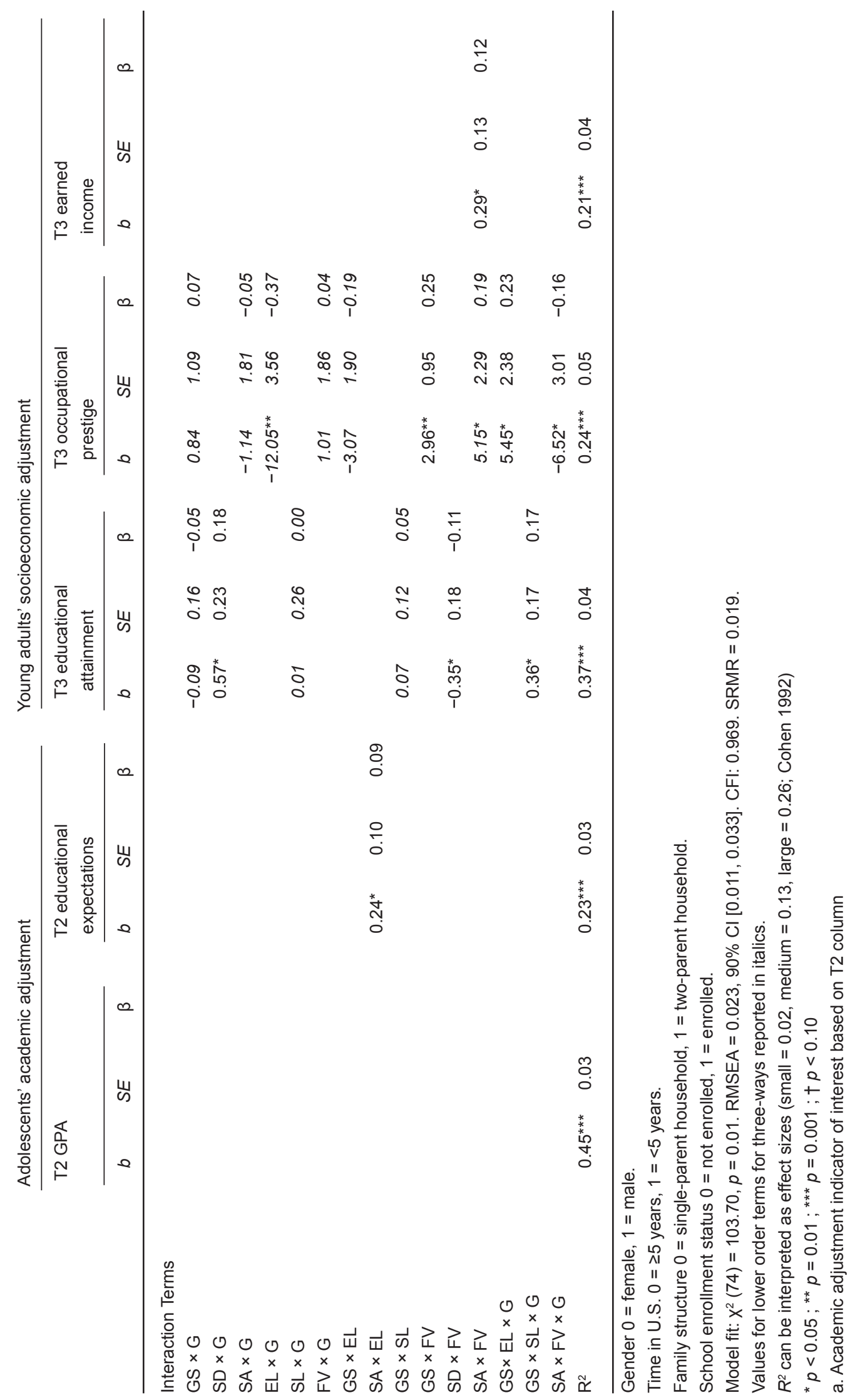




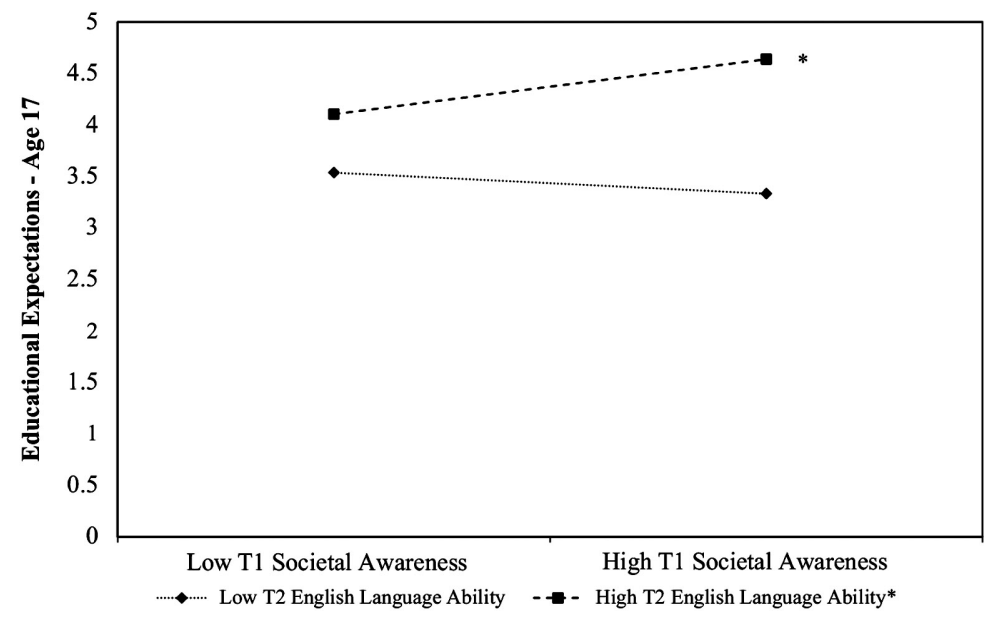

Figure 3 Association between adolescents' awareness of societal discrimination (T1) and adolescents' educational expectations (T2) as moderated by English language ability (Aim 2). ${ }^{*} p<0.05$

English language ability (T2), there were direct effects, as well as interaction effects. Starting with the direct effects, English language ability related to adolescents increased educational expectations and higher levels of occupational prestige in early adulthood. Turning to the interaction effects, in predicting educational expectations, adolescents' English language ability interacted with awareness of societal discrimination. Under conditions of high English language ability, high levels of societal discrimination related to increased levels of educational expectations, $b=0.18, S E=0.09, p=0.04$, whereas, under low conditions, there was no association, $b=-0.07, S E=0.07, p=0.36$ (Figure 3). In predicting occupational prestige, there was a 3-way interaction between gender, English language ability, and perceived general discrimination, yet there were no significant simple slopes (females: $b=-2.66, S E=1.69, p$ $=0.12$; males: $b=2.75, S E=1.57, p=0.08$ ) (Aim 3).

Turning to Spanish language ability (T2), there were no direct effects. In predicting educational attainment, there was a 3-way interaction with gender, Spanish language ability, and perceived general discrimination (Figure 4; Aim 3). This interaction was significant for male youth, $b=0.42, S E=0.15, p=0.01$, but not female youth, $b=0.10, S E=$ $0.10, p=0.34$. Under conditions of low Spanish language ability, high levels of male adolescents' perceptions of general discrimination related to lower educational attainment in early adulthood (risk factor), $b=-0.41$, 


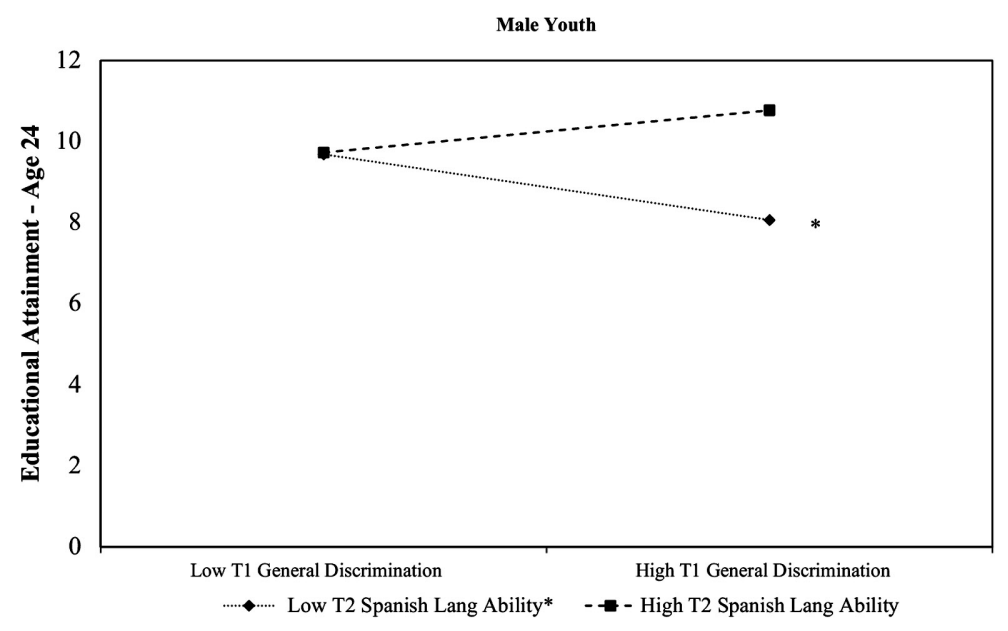

Figure 4 Association between adolescents' perceived general discrimination (T1) and young adult educational attainment (T3) as moderated by Spanish language ability and gender (Aim 3). ${ }^{*} p<0.05$

$S E=0.14, p=0.004$. Under conditions of high Spanish language ability, there was no association between male adolescents' perceptions of general discrimination and educational attainment in early adulthood (protective factor), $b=0.26, S E=0.16, p=0.105$.

For familism values (T2), there were direct effects, as well as interaction effects. Starting with the direct effects, results were contrary to hypotheses and suggested that high levels of familism values related to adolescents decreased educational expectations and lower levels of occupational prestige (Table 2). Turning to the interaction effects, familism values interacted with all the discrimination predictors. In predicting educational attainment, familism values interacted with perceived school discrimination (Figure 5). Under conditions of high levels of adolescents' familism values, high levels of perceived school discrimination related to lower levels of educational attainment in early adulthood (exacerbates risk), $b=-0.66, S E=0.20, p=0.001$, whereas under low levels, there was no association, $b=-0.21, S E=0.16, p=0.193$.

In predicting occupational prestige, there were two interactions. First, there was an interaction between familism values and perceived general discrimination (Figure 6). Under conditions of high levels of adolescents' familism values, high levels of adolescent perceptions of general discrimination related to higher levels of occupational prestige in early adulthood (reactive factor), $b=2.24, S E=1.13, p=0.047$, whereas under 


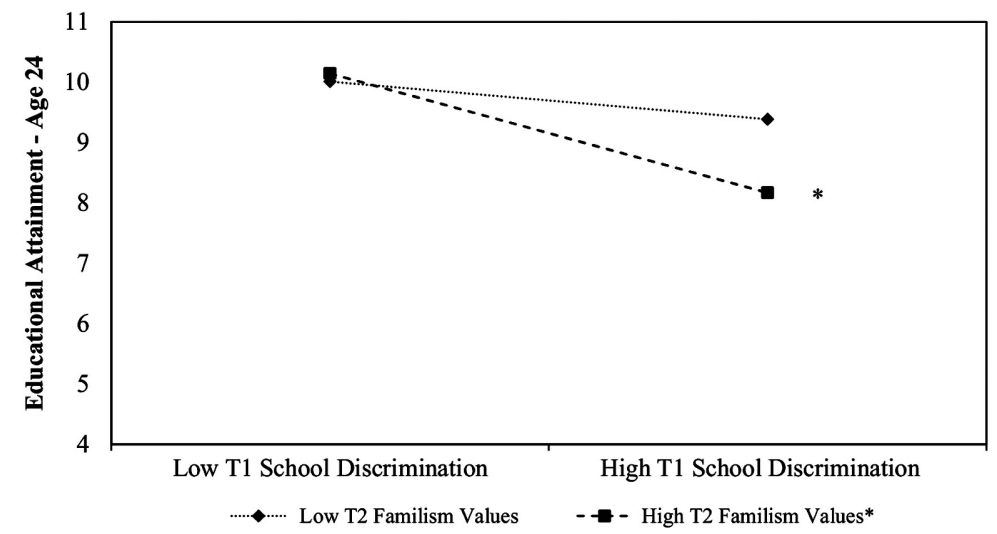

Figure 5 Association between adolescents' perceived school discrimination (T1) and young adult educational attainment (T3) as moderated by familism values (Aim 2). ${ }^{*} p<0.05$

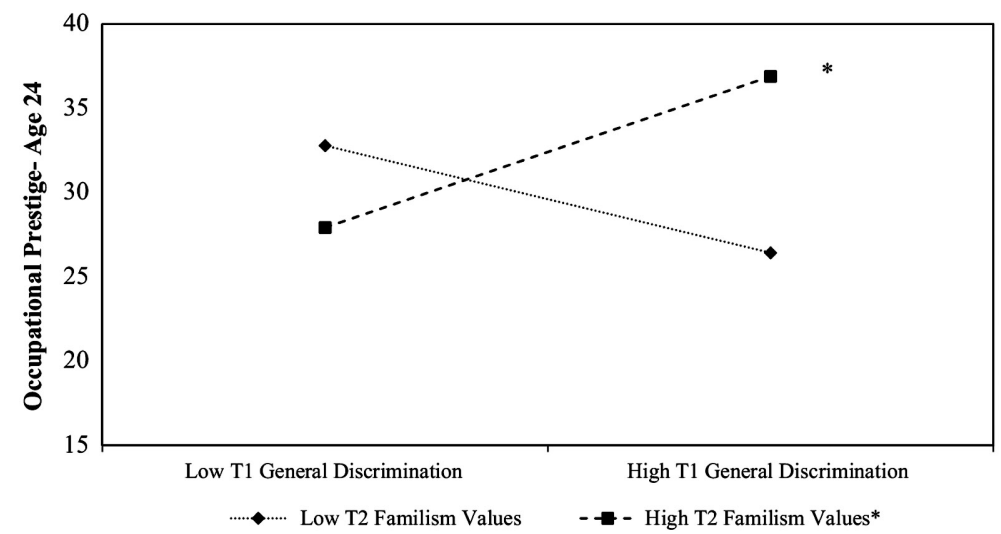

Figure 6 Association between adolescents' perceived general discrimination (T1) and young adult occupational prestige (T3) as moderated by familism values (Aim 2). ${ }^{*} p<0.05$

low levels, there was no association, $b=-1.59, S E=0.99, p=0.107$. Second, there was a three-way interaction between gender, familism values, and adolescents' awareness of societal discrimination (Figure 7; Aim 3). The interaction was significant for female youth, $b=4.82, S E=$ 2.02, $p=0.017$, but not male youth, $b=-0.87, S E=2.36, p=0.714$. Under conditions of high levels of female adolescents' familism values, high levels of awareness of societal discrimination related to higher occupational prestige (reactive factor), $b=3.69, S E=1.85, p=0.046$, whereas, there was no association under low levels of familism values, $b=-2.71$, $S E=1.77, p=0.127$. 


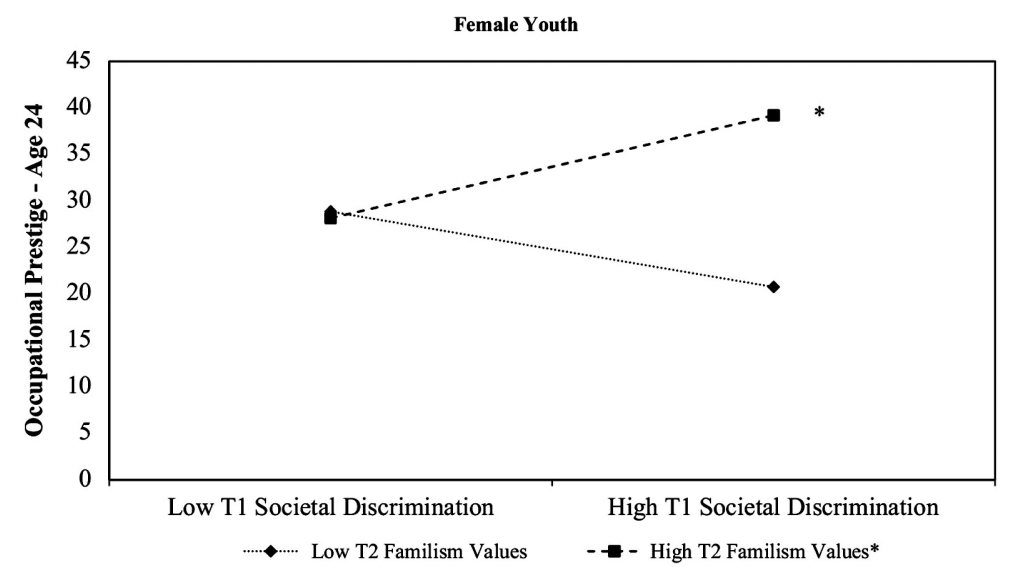

Figure 7 Association between adolescents' awareness of societal discrimination (T1) and young adult occupational prestige (T3) as moderated by familism values and gender (Aim 3). ${ }^{*} p<0.05$

In predicting earned income, there was an interaction between familism values and awareness of societal discrimination. Follow-up analyses suggest that there were no significant simple slopes (high levels: $b=0.22, S E=0.12, p=0.062$; low levels: $b=-0.15, S E=0.12, p=$ $0.216)$.

\section{Discussion}

The negative consequences of perceived discrimination on youth developmental outcomes and health have long been the focus of research addressing mechanisms of social stratification among ethnic minority populations (Araújo and Borrell 2006; Benner et al. 2018). However, to date, few studies have examined the long-term, differential associations of adolescents' awareness of and perceived sources of discrimination with early adult attainment among Mexican-origin immigrant families. Examining the associations between different experiences with social stratification during adolescence, including awareness of discrimination/racism in society and interpersonal experiences of discrimination from different sources, to indicators of young adults' socioeconomic attainment and the role of academic and cultural factors provides new insights into longitudinal, distal mechanisms of how and among whom the effects are most salient across adolescence into early adulthood. The 
current study among Mexican-origin immigrant families found evidence of long-term linkages with socioeconomic attainment during early adulthood. The findings highlight the importance of examining multiple aspects of how social stratification might impact youth development, as there was evidence of variation in the linkages depending on the source. This study also found support for specific mechanisms linking aspects of social stratification to socioeconomic attainment (i.e., educational attainment and occupational prestige), including the mediating role of adolescents' GPA. The current investigation also expands the literature by testing alternative theories of the role of adaptive culture as either reducing risk (promotive role; mediation) or buffering (protective role; moderation) the negative effects of awareness of societal discrimination and perceived discrimination across sources. The study found evidence of the moderating role of adaptive culture, with variation by the indicators of cultural orientation.

\section{Awareness of and Perceived School and General Discrimination Linked to Socioeconomic Attainment}

Based on theory (Stein et al. 2016) and meta-analytic work with youth (Benner et al. 2018) and adults (Araújo and Borrell 2006), it was hypothesized that higher levels of adolescents' awareness of and perceived school and general discrimination would be associated with poorer academic and socioeconomic outcomes. When examining the three indicators, awareness of societal discrimination emerged as the most robust predictor of later academic adjustment and socioeconomic attainment. The pattern of findings for adolescents' societal awareness of discrimination, though, was in contrast with hypotheses as the association was positive, relating to increased GPA during adolescence and higher educational attainment in early adulthood. The associations were both direct and indirect though adolescents' increased GPA and, in turn, resulting in higher educational attainment and occupational prestige. The prior literature on this aspect of social stratification is limited (Diemer et al. 2016). The findings from the current study align more closely with literature on educational contexts and stereotype threat (i.e., fear of confirming negative stereotype; one's personal failure reflects negatively on the group; Baysu et al. 2011). This literature suggests that outgroup threat may provoke either a detrimental response or, as in the current study, a 
challenge response resulting in increased persistence and motivation to succeed (Baysu et al. 2011). In qualitative work, Sanders (1997) found for African Americans that they viewed racism as a challenge and opportunity to work harder. The findings also align with more recent theoretical work on the importance of critical consciousness for marginalized groups (Diemer et al. 2016). This work purports that for these youth, awareness of mechanisms of social stratification may offer youth more agency in being able respond to injustice; similar to the research on outgroup threat prompting these youth to respond in positive, rather than negative, ways (Diemer et al. 2016). For the other indicators of perceived discrimination, there were no direct associations in the full sample. These null findings may be due to the nature of the measures that were available for use in this secondary data analysis study. These measures may not have been sensitive or robust enough to capture the true relationship between perceived discrimination and outcomes. Ultimately, future research is needed to further understand the conditions under which youth may respond in a reactionary or challenging manner to discriminatory messages relevant to their ethnic group to be able to promote positive development for these youth.

\section{The Role of Adaptive Culture}

Seeking to better understand the role of adaptive culture, including indicators of cultural orientation (i.e., English Language ability representing mainstream orientation, Spanish language ability and familism values representing Mexican orientation), both promotive (direct and mediation effects) and protective (moderation) mechanisms were considered. The current study lends evidence to the primarily supportive role of adaptive culture in moderating the links between discrimination and socioeconomic attainment. In particular, there was evidence for young men only that high Spanish language ability as protective factor, mitigating the effects of general discrimination on educational attainment; whereas, low Spanish ability was a risk factor for higher levels of general discrimination linking to lower educational attainment. These findings highlight the importance of the retention of Spanish language ability as a way to reduce the negative influence of discrimination on socioeconomic outcomes and are consistent with other studies identifying the protective nature of cultural affiliation on other domains of wellbeing 
(Delgado et al. 2011). Furthermore, under conditions of high English language ability, awareness of societal discrimination related to increased levels of educational expectations during adolescence. Similarly, under conditions of high levels of adolescents' familism values, general discrimination related to higher levels of occupational prestige. Taken together, these findings including English language ability may suggest the importance of navigating both cultural contexts; both Mexican and Anglo orientations provide sources of strength for these youth. This may suggest that youth who can navigate both mainstream and Mexican culture have a cultural advantage (Perez-Brena et al. 2018). This proposition, though, will need to be tested directly in future work with a direct and robust measure of biculturalism. There was only one finding for adaptive culture that may suggest a Mexican orientation may exacerbate risk. This is in line with scholarship that finds some adaptive cultural systems fail to promote development (White et al. 2018). This finding suggests that under condition of high familism values, perceptions of school discrimination related to lower levels of educational attainment. As with the finding for female adolescents (discussed at more length below), school discrimination may be especially salient domain specific experience in its relationship to educational attainment. Consistent with other work with ethnic minority samples (Baysu et al. 2011), for females and youth who highly value familism, sources of school discrimination are detrimental because it also threatens a context they are likely to be particularly close to (home); whereas with other sources of discrimination, adaptive culture is playing more of a protective role. Additional research is needed to understand under what conditions youth might persist despite unwelcoming school environments, versus when discrimination has a more detrimental effect.

\section{The Role of Gender}

The current study highlights the importance of examining variation by gender in understanding the nuanced associations between sources of discrimination and socioeconomic outcomes for Mexican-origin youth. For young men only, perceptions of general discrimination related to poor outcomes within a particular subgroup based on language ability (i.e., lower educational attainment for those with low Spanish language ability; risk process). Similarly, for young women only, perceptions of 
discrimination within the school context related to poor outcomes (i.e., lower educational attainment). These findings are consistent with the larger literature related to the negative impact of discrimination (Benner et al. 2018), but adds understanding related to cultural (discussed previously) and domain mechanisms (Benner and Graham 2013). Findings suggest that for young women, under conditions of high familism values, awareness of societal discrimination related to better outcomes (i.e., higher occupational prestige). This finding provides additional support for the idea that females with a stronger orientation toward their cultural group may respond to stereotype threat by challenging these notions. These findings may point to the importance of being aware and/or prepared for discriminatory experiences. The findings for young women overall are in contrast with prior studies that more consistently found stronger links for males compared to females during adolescence (Benner et al. 2018). This may reflect the family context of gendered socialization (Raffaelli and Ontai 2004); girls may have closer affiliations with home, additional support from parents, and place high value on family relationships, which therefore are protective for them. Yet, few studies have attended to gender variation in the links between discrimination and socioeconomic outcomes during early adulthood or the role of adaptive culture (Araújo and Borrell 2006). Thus, it will be important for future research to investigate more nuanced questions related to the conditions that discrimination has a varied impact for young women as compared to men.

\section{Limitations}

Despite this study's contributions, the findings should be evaluated with the limitations in mind. First, the sample used was limited to Mexicanorigin adolescents from only two areas of the U.S. However, this sample was chosen due to Mexican-origin youth continuing to make up the largest group of immigrants in the U.S. (López et al. 2018) and when compared to other ethnic minorities are at disparate risk for low levels of socioeconomic attainment (Portes and Rumbaut 2001). Future research should seek to examine these relations in Mexican-origin samples across other regional areas of the U.S. Second, several measures were limited to one item each (e.g., youth educational expectations) given the secondary analysis approach of existing data. Moreover, several other variables 
(e.g., perceived general discrimination, familism values) were measured with the use of only a few items, thereby capturing only limited aspects of these broader, multidimensional constructs. Moreover, for mainstream orientation, only one measure was used, English language ability. This measure only captures behavioral aspects of this orientation. The use of an existing dataset, though with numerous benefits, such as the inclusion of a large sample size, limited the use of more thorough assessments of certain constructs. Future studies should seek to include measures that are more comprehensive in capturing constructs, including multiple measures capturing additional aspects of social stratification and cultural orientations. Third, though the current study includes individual and cultural variables of relevance to Mexican-origin youth's socioeconomic attainment, certain other intervening factors, such as parent involvement and perceptions of school climate and school racial composition, were not examined. Future research might aim to include family- and school-related constructs in examining Mexican-origin youth's attainment. Fourth, the salience of results may be limited by the age of the data (collected approximately 20 years ago). There have been changes in the cultural experience of Mexican-origin adolescents within the U.S. (e.g., increased linguistic diversity, income inequality, and diversity in legal status; Rumbaut 2014), whereas, many aspects of their cultural and contextual experience (e.g., educational attainment, school segregation, family cultural variables) have remained consistent (Rumbaut 2014). Thus, the results of this study may hold significance. Further, the unique nature of this data (large immigrant sample) allows for the engagement in studies that contribute to theories regarding student, school, and family factors, with the understanding that additional studies, using local and more recent data, will contribute to a more nuanced understanding of the topic.

\section{Implications}

This study provides implications for a multifaceted approach to programing promoting positive development among Mexican-origin youth during transitional periods. There is a critical need to focus on largescale, systemic efforts to reduce prejudice and discrimination that maintain disparities among immigrant youth and families. This would be a more equitable approach to combatting the effects of social stratification 
as compared to focusing solely on youth and families from marginalized groups carrying the weight of change. In conjunction with systemic efforts for change, programs focused on resilience efforts for individual youth might include components that fortify Mexican-origin youth's Mexican cultural orientations (e.g., Spanish language ability, familism values) as this connection to their ethnic group provides a source of strength and potential coping mechanisms within the context of social stratification in the U.S. As results point to the importance of the retention of youth's Spanish language ability, policies that limit Spanish speaking in schools and other spaces could have the potential to increase the negative impact of discrimination. In addition, the findings for English language ability underscores the potential benefit of biculturalism for these youth. Thus, not only retaining a connection with their ethnic group, but also embracing positive aspects of mainstream U.S. culture, may provide additional protective resources. An example of how this might be implemented is STRONG, a school-based program for newcomer immigrant youth that includes a session on identifying cultural strengths and orientations (Crooks et al. 2020). Consistent with the current study, this program shows promise in promoting adaptive culture as a mechanism to increase youth resilience and reduce stress, ultimately support positive development. Moreover, for youth from immigrant families, the results seem to point to the importance of having an awareness of the societal context of prejudice and discrimination in the U.S. that could potentially provide a source of strength by challenging these notions through hard work and persistence in the context of risk. From a programing perspective, these findings suggest the promise of the support and/or the development of awareness of prejudice and discrimination as a way for marginalized groups of adolescents and young adults to have more agency when facing social inequalities.

\section{Conclusion}

The current study addressed existing gaps in the literature related to the long-term links between social stratification mechanisms during adolescence and socioeconomic attainment during early adulthood using an ethnic-homogenous design among youth in Mexican-origin immigrant families. Findings provide preliminary evidence of the long-term 
consequences of adolescents' awareness of societal discrimination in relation to race, ethnicity, and immigrant status consistently relating to positive outcomes for the whole sample and within subgroups by gender and adaptive culture. The study also suggested the importance of examining within-group variability, extending knowledge of the role of adaptive culture and gender on the negative distal effects of adolescents' perceived discrimination for youth in Mexican-origin immigrant families. For youth with high English language ability and familism values, there were positive links between awareness of and general discrimination and socioeconomic outcomes, suggesting potentially a reactionary mechanism. Findings also highlight that the protective role of adaptive culture varied by gender; for young women familism values and for young mean retention of Spanish language ability. Yet, there was one instance that familism values exacerbated risk in the relation between school discrimination and educational attainment; highlighting that sources of discrimination within the school context may be particularly detrimental for those youth closely connected to their culture of origin. The nuanced insights from the current study offer potential avenues for addressing disparities and closing gaps by fostering academic development, adaptive culture, and socioeconomic attainment for youth in Mexican immigrant families.

Acknowledgments The data come for the Children of Immigrants Longitudinal Study (CILS; 1991-2006; Portes and Rumbaut 1991-2006). The funders of the original study included the Russell Sage Foundation, the Andrew W. Mellon Foundation, the Spencer Foundation, and the National Science Foundation. The current study involved a retrospective/secondary analysis of data from the original CILS study. Portions of this manuscript were presented at the National Council for Family Relations Annual Meetings (November 2016 [Austin, TX], 2018 [San Diego, CA]).

Authors' Contributions L.A.W. conceived of the study, participated in its design and coordination, performed statistical analysis and interpretation of the data, and drafted the manuscript; P.G.A. participated in the study design and coordination, interpretation of the data, and helped to draft the manuscript; M.Y.D. participated in the interpretation of the data and helped to draft the manuscript. All authors read and approved the final manuscript.

Data Sharing and Declaration The dataset analyzed during the current study are available in the Inter-University consortium for Political and Social Research (ICPSR) repository, https://www.icpsr.umich.edu/icpsrweb/ICPSR/studies/20520 (Portes and Rumbaut 1991-2006). 
Conflict of Interest The authors declare that they have no conflict of interest.

Ethical Approval The original study had appropriate Internal Review Board approval. The study was performed in accordance with ethical standards as laid down in the 1964 Declaration of Helsinki. The current study did not require Internal Review Board approval per U.S. Department of Health and Human Services guidelines (https://www. hhs.gov/ohrp/regulations-and-policy/decision-charts/index.html ); the data were not identifiable.

Informed Consent Informed consent/assent was obtained by the original study authors. Portes and Rumbaut (1991-2006).

\section{References}

Adam, E. K., Heissel, J. A., Zeiders, K. H., Richeson, J. A., Ross, E. C., Ehrlich, K. B., \& Eccles, J. S. (2015). Developmental histories of perceived racial discrimination and diurnal cortisol profiles in adulthood: a 20-year prospective study. Psychoneuroendocrinology, 62, 279-291. https://doi.org/10.1016/j. psyneuen.2015.08.018

Aiken, L. S., \& West, S. G. (1991). Multiple regression: testing and interpreting interactions. Newbury Park, CA: Sage.

Alfaro, E. C., Umaña-Taylor, A. J., Gonzales-Backen, M. A., Bámaca, M. Y., \& Zeiders, K. H. (2009). Latino adolescents' academic success: the role of discrimination, academic motivation, and gender. Journal of Adolescence, 32, 941-962.

Araújo, B. Y., \& Borrell, L. N. (2006). Understanding the link between discrimination, mental health outcomes, and life chances among Latinos. Hispanic Journal of Behavioral Sciences, 28, 245-266.

Baysu, G., Phalet, K., \& Brown, R. (2011). Dual identity as a two-edged sword: identity threat and minority school performance. Social Psychology Quarterly, 74, 121-143.

Benner, A. D., \& Graham, S. (2011). Latino adolescents' experiences of discrimination across the first 2 years of high school: correlates and influences on educational outcomes. Child Development, 82, 508-519.

Benner, A. D., \& Graham, S. (2013). The antecedents and consequences of racial/ ethnic discrimination during adolescence: does the source of discrimination matter? Developmental Psychology, 49, 1602-1613.

Benner, A. D., \& Kim, S. Y. (2009). Experiences of discrimination among Chinese American adolescents and the consequences for socioemotional and academic development. Developmental Psychology, 45, 1682-1694. https://doi. org/10.1037/a0016119

Benner, A. D., Wang, Y., Shen, Y., Boyle, A. E., Polk, R., \& Cheng, Y. P. (2018). Racial/ ethnic discrimination and well-being during adolescence: a meta-analytic review. American Psychologist, 73, 855-883. 
Berkel, C., Knight, G. P., Zeiders, K. H., Tein, J., Roosa, M. W., Gonzales, N. A., \& Saenz, D. (2010). Discrimination and adjustment for Mexican American adolescents: a prospective examination of the benefits of culturally related values. Journal of Research on Adolescence, 20, 893-915.

Blair, S. L., \& Cobas, J. A. (2006). Gender differences in young Latino adults' status attainment: understanding bilingualism in the familial context. Family Relations, 55, 292-305.

Brown, C. S., \& Chu, H. (2012). Discrimination, ethnic identity, and academic outcomes of Mexican immigrant children: the importance of school context. Child Development, 83, 1477-1485.

Cavanaugh, A. M., Stein, G. L., Supple, A. J., Gonzalez, L. M., \& Kiang, L. (2018). Protective and promotive effects of Latino early adolescents' cultural assets against multiple types of discrimination. Journal of Research on Adolescence, 28, 310-326.

Chiswick, B., \& Miller, P. (2007). The economics of language: international analysis. New York, NY: Routledge, Taylor \& Francis Group.

Cohen, J. (1992). A power primer. Psychological Bulletin, 112, 155-159.

Crooks, C. V., Hoover, S., \& Smith, A. C. (2020). Feasibility trial of the school-based STRONG intervention to promote resilience among newcomer youth. Psychology in the Schools, https://doi.org/10.1002/pits.22366

Delgado, M. Y., Updegraff, K. A., Roosa, M. W., \& Umaña-Taylor, A. J. (2011). Discrimination and Mexican-origin adolescents' adjustment: the moderating roles of adolescents', mothers', and fathers' cultural orientations and values. Journal of Youth and Adolescence, 40, 125-139.

Delgado, M. Y., Nair, R. L., Zeiders, K. H., \& Jones, S. K. (2019). Latino adolescents' experiences with ethnic discrimination: moderating factors and mediating mechanisms. In H. Fitzgerald, D. Johnson, D. Qin, F. Villarruel \& J. Norder (Eds), Handbook of children and prejudice. Cham: Springer.

Diemer, M., Rapa, L., Voight, A., \& McWhirter, A. (2016). Critical consciousness: a developmental approach to addressing marginalization and oppression. Child Development Perspectives, 10, 216-221. https://doi.org/10.1111/cdep.12193

Dumka, L., Gonzales, N., Bonds, D., \& Millsap, R. (2009). Academic success of Mexican origin adolescent boys and girls: the role of mothers' and fathers' parenting and cultural orientation. Sex Roles, 60, 588-599.

Enders, C. K. (2010). Applied missing data analysis. New York, NY: Guilford.

Finch, B. K., Kolody, B., \& Vega, W. A. (2000). Perceived discrimination and depression among Mexican-origin adults in California. Journal of Health and Social Behavior, 41, 295-313.

Fritz, M. S., Taylor, A. B., \& MacKinnon, D. P. (2012). Explanation of two anomalous results in statistical mediation analysis. Multivariate Behavioral Research, 47, 61-87.

Galambos, N. L., \& Krahn, H. J. (2008). Depression and anger trajectories during the transition to adulthood. Journal of Marriage and Family, 70, 15-27. 
Germán, M., Gonzales, N. A., \& Dumka, L. (2009). Familism values as a protective factor for Mexican-origin adolescents exposed to deviant peers. The Journal of Early Adolescence, 29, 16-42.

Gonzales, N. A., Knight, G. P., Birman, D., \& Sirolli, A. A. (2004). Acculturation and enculturation among Latino youth. In K. Maton, C. Schellenbach, B. Leadbeater \& A. Solarz (Eds), Investing in children, youth, families, and communities; strengthsbased research and policy (pp. 285-302). Washington, DC: American Psychological Association.

Gonzales, N. A., Germán, M., Kim, S. Y., George, P., Fabrett, F. C., Millsap, R., \& Dumka, L. E. (2008). Mexican American adolescents' cultural orientation, externalizing behavior and academic engagement: the role of traditional culture values. American Journal of Community Psychology, 41, 151-164.

Greene, M., Way, N., \& Pahl, K. (2006). Trajectories of perceived adult and peer discrimination among Black, Latino, and Asian American adolescents: patterns and psychological correlates. Developmental Psychology, 42, 218-238.

Hu, L., \& Bentler, P. M. (1999). Cutoff criteria for fit indexes in covariance structure analysis: conventional criteria versus new alternatives. Structural Equation Modeling, 6, 1-55.

Huynh, V. W., \& Fuligni, A. J. (2010). Discrimination hurts: the academic, psychological, and physical well-being of adolescents. Journal of Research on Adolescence, 20, 916-941.

Kline, R. B. (2011). Principles and practice of structural equation modeling. New York, NY: Guilford.

López, M. H., Bialik, K., \& Radford, J. (2018). Key findings about U.S. immigrants. Washington, DC: Pew Research Center. http://www.pewresearch.org/ fact-tank/2018/09/14/key-findings-about-u-s-immigrants/

Martinez, G., \& Bámaca-Colbert, M. Y. (2019). A reciprocal and longitudinal investigation of peer and school stressors and depressive symptoms among Mexican-origin adolescent females. Journal of Youth and Adolescence, 48, 21252140. https://doi.org/10.1007/s10964-019-01091-2

McFarland, J., Hussar, B., de Brey, C., Snyder, T., Wang, X., Wilkinson- Flicker, S., Gebrekristos, S., Zhang, J., Rathbun, A., Barmer, A., Bullock Mann, F., \& Hinz, S. (2017). The condition of education 2017 (NCES 2017-144).Washington, DC: U.S. Department of Education. National Center for Education Statistics. https://nces. ed.gov/pubsearch/pubsinfo.asp?pubid=2017144 Accessed 4 Sep 2019.

Medvedeva, M. (2010). Perceived discrimination and linguistic adaptation of adolescent children of immigrants. Journal of Youth and Adolescence, 39, 940-952.

Muthén, L. K., \& Muthén, B. O. (1998-2014). Mplus user's guide. 7th edition. Los Angeles: Muthén \& Muthén.

Perez-Brena, N. J., Rivas-Drake, D., Toomey, R. B., \& Umana-Taylor, A. J. (2018). Contributions of the integrative model for the study of developmental competencies in minority children: what have we learned about adaptive culture? American Psychologist, 73, 713-726. 
Piña-Watson, B., Lorenzo-Blanco, E. I., Dornhecker, M., Martinez, A. J., \& Nagoshi, J. L. (2016). Moving away from a cultural deficit to a holistic perspective: traditional gender role values, academic attitudes, and educational goals for Mexican descent adolescents. Journal of Counseling Psychology, 63, 307-318. https://doi. org/10.1037/cou0000133

Portes, A., \& Bach, R. L. (1985). Latin journey: Cuban and Mexican immigrants in the United States. Berkley: University of California Press.

Portes, A., \& Rumbaut, R. G. (1991-2006). Children of immigrants longitudinal study (CILS). ICPSR20520-v2. Ann Arbor, MI: Inter-university Consortium for Political and Social Research. https://doi.org/10.3886/ICPSR20520.v2

Portes, A., \& Rumbaut, R. G. (2001). Legacies: the story of the immigrant second generation. Berkeley/New York, NY: University of California Press/Russell Sage Foundation. Raffaelli, M., \& Ontai, L. L. (2004). Gender socialization in Latino/a families: results from two retrospective studies. Sex Roles, 50, 287-299.

Ríos-Salas, V., \& Larson, A. (2015). Perceived discrimination, socioeconomic status, and mental health among Latino adolescents in US immigrant families. Children and Youth Services Review, 56, 116-125.

Rivas-Drake, D., Hughes, D., \& Way, N. (2009). A preliminary analysis of associations among ethnic-racial socialization, ethnic discrimination, and ethnic identity among urban sixth graders. Journal of Research on Adolescence, 19, 558-584.

Roche, K. M., Calzada, E. J., Ghazarian, S. R., Little, T. D., Lambert, S. F., \& Schulenberg, J. (2017). Longitudinal pathways to educational attainment for youth in Mexican and Central American immigrant families. Journal of Latina/o psychology, 5, $12-26$.

Roche, K. M., Ghazarian, S. R., \& Fernandez-Esquer, M. E. (2012). Unpacking acculturation: cultural orientations and educational attainment among Mexicanorigin youth. Journal of Youth and Adolescence, 41, 920-931.

Roosa, M. W., O’Donnell, M., Cham, H., Gonzales, N. A., Zeiders, K. H., Tein, J. Y., \& Umaña-Taylor, A. (2012). A prospective study of Mexican American adolescents' academic success: considering family and individual factors. Journal of Youth and Adolescence, 41, 307-319.

Rumbaut R. G. (2014). Using NCES surveys to understand the experiences of immigrant-origin students. Paper presented at the National Academy of Education's Workshop to Examine Current and Potential Uses of NCES Longitudinal Surveys by the Education Research Community, Washington, DC.

Sanders, M. G. (1997). Overcoming obstacles: academic achievement as a response to racism and discrimination. Journal of Negro Education, 66, 83-93.

Santiago, C. D., Gudiño, O. G., Baweja, S., \& Nadeem, E. (2014). Academic achievement among immigrant and US-born Latino adolescents: associations with cultural, family, and acculturation factors. Journal of Community Psychology, 42, 735-747.

Seider, S., Clark, S., Graves, D., Kelly, L. L., Soutter, M., El-Amin, A., \& Jennett, P. (2019). Black and Latinx adolescents' developing beliefs about poverty and associations with their awareness of racism. Developmental Psychology, 55, 509-524. 
Snyder, T. D., de Brey, C., \& Dillow, S. A. (2019). Digest of education statistics 2017 (NCES 2018-070). Washington, DC: National Center for Education Statistics, Institute of Education Sciences. U.S. Department of Education. https://nces. ed.gov/pubs2018/2018070.pdf

Stein, G. L, Gonzales, R. G, Coll, C. G., \& Prandoni, J. I. (2016). Latinos in rural, new immigrant destinations: a modification of the integrative model of child development. In L. J. Crockett, C. Gustavo (Eds). Latinos in rural, new immigrant destinations: a modification of the integrative model of child development. rural ethnic minority youth and families in the United States (pp. 37-56). Cham: Springer.

Stone, S., \& Han, M. (2005). Perceived school environments, perceived discrimination, and school performance among children of Mexican immigrants. Children and Youth Services Review, 27, 51-66.

Sum, A., Khatiwada, I., McLaughlin, J., \& Palma, S. (2009). The consequences of dropping out of high school. Boston, MA: Center for Labor Market Studies Publications.

Treiman, D. J. (1977). Occupational prestige in comparative perspective. New York, NY: Academic Press.

Umaña-Taylor, A. J., Wong, J. J., Gonzales, N. A., \& Dumka, L. E. (2012). Ethnic identity and gender as moderators of the association between discrimination and academic adjustment among Mexican-origin adolescents. Journal of Adolescence, $35,773-786$.

Urban Institute. (2009). Children of immigrants: Immigration trends. Washington, DC: Urban Institute. https://www.urban.org/sites/default/files/ publication/31001/901292-children-of-immigrants-immigration-trends.pdf

U.S. Census Bureau. (2017). Facts for features: Hispanic heritage month 2017. Washington, DC: U.S. Census Bureau. https://www.census.gov/content/dam/ Census/newsroom/facts-for-features/2017/cb17-ff17.pdf

U.S. Census Bureau. (2019). Facts for features: Hispanic heritage month 2019. Washington, DC: U.S. Census Bureau. https://www.census.gov/content/dam/ Census/newsroom/facts-for-features/2019/hispanic-heritage-month.pdf

White, R., Nair, R. L., \& Bradley, R. H. (2018). Theorizing the benefits and costs of adaptive cultures for development. American Psychologist, 73(6), 727-739.

Wigfield, A., \& Cambria, J. (2010). Expectancy-value theory: retrospective and prospective. In S. Karabenick, T. Urdan (Eds). Advances in motivation and achievement. the next decade of research on motivation (Vol. 16) (pp. 35-70). New York, NY: Taylor Francis Group. https://doi.org/10.1108/ $\underline{\text { S0749-7423(2010)000016A005 }}$

Zeiders, K. H., Umaña-Taylor, A. J., Martinez-Fuentes, S., Updegraff, K. A., Douglass Bayless, S., \& Jahromi, L. B. (2018). Latina/o youth' discrimination experiences in the U.S. Southwest: estimates from three studies. Applied Developmental Science, 73, 855-883. https://doi.org/10.1080/10888691.2018.1527695 


\section{About the Authors}

Lorey A. Wheeler is an Associate Research Professor in the Nebraska Center for Research on Children, Youth, Families and Schools and the Co-Director of the Nebraska Academy for Methodology, Analytics and Psychometrics at the University of NebraskaLincoln. Her major research interests include the role of family and cultural contexts in development, including psychosocial adjustment, interpersonal relationships, and educational and occupational attainment among minoritized and understudied populations, particularly those of Mexican origin.

Prerna G. Arora is an Assistant Professor of Psychology in the Department of Health and Behavior Studies at Teachers College, Columbia University. Her major research interests include issues of access and quality of mental health care for underserved youth and adolescents.

Melissa Y. Delgado is an Associate Professor of Family Studies and Human Development in the Norton School of Family and Consumer Sciences at The University of Arizona. Her major research interests include the mechanisms that reduce racial/ethnic inequality (e.g., educational) and promote Latinx youth's positive development across early to late adolescence, particularly for youth of Mexican origin. 